\title{
Broaden research on the human dimensions of climate change
}

To the Editor - Human actions are causing global environmental changes that, in turn, have significant human impacts and demand human responses. The magnitude of change, impact and response will only increase in the decades to come. For too long science, technology, engineering and mathematics (STEM) subjects have dominated research into how people are altering the atmosphere, biosphere, cryosphere, hydrosphere and lithosphere ${ }^{1,2,3}$. We now urgently need to understand, and seek to alter, human behaviour so that our planet remains a liveable one for all people ${ }^{4}$.

In this light, the recent joint Collection of articles published by Nature Climate Change and Nature Energy is extremely welcome (http://www.nature.com/ energyclimatesociety). It showcases the need for, and value of, environmental social science.

Happily, the new UN Sustainable Development Goals promote the need for STEM subjects and the social sciences to play equal roles in forging a better world (http://go.nature.com/28TEATX). Likewise 'Future Earth' - the new global platform for environmental change research - is committed to parity of esteem across the disciplines as part of its focus on integrated inquiry that joins the proverbial dots (http://go.nature.com/28REB9y). However, there is more than one way to comprehend so-called human dimensions in descriptive, explanatory and normative terms.

The Nature Climate Change papers in the joint Collection fail to acknowledge this plurality, to varying degrees, with only the contribution by Geels, Berkhout and van Vuuren making this clear ${ }^{5}$. The others create the false impression that the study of societies is analogous to the study environmental systems: their authors imply that with the 'right' concepts, models, questions and evidence one can derive a fairly objective understanding of the people-climate-energy nexus. They create a sense that different social scientific experts are looking at different parts of a single social jigsaw, such that the pieces can in principle be connected to reveal the social whole. Epistemic realism and ontological monism here work in tandem. Equipped with such accurate and complete understanding, the further implication is that one may know 'what works' when designing policies to change human behaviour. Critically, what gets lost in these studies is that a 'scientized' understanding of society is not the only - nor necessarily best or most appropriate - approach to human affairs ${ }^{6}$.

Prospering since the early 1990s, environmental social science is a vibrant enterprise spanning multiple disciplines ${ }^{7}$. Though some commentators suggest otherwise ${ }^{8}$, it is philosophically, theoretically, topically and methodologically plural. This is because only by abstracting from complex and varied cultural, economic, political and biophysical contexts can one presume to identify 'essential' or 'true' information about peoples' perceptions, norms, preferences, values or practices.

Alternatively, claiming to 'accurately' understand human thought and action 'in context' only works if one ignores the many theoretical, methodological, analytical and normative approaches available to comprehend society. Many social scientists reject the idea that their disciplines can and should be modelled on the sciences of human and non-human nature ${ }^{9,10}$. Many environmental social scientists are dismayed that only a narrow intellectual slice of their domain is seen by some to be relevant to the 'grand challenges' of our time ${ }^{1,11}$. Currently, mainstream economics, behavioural psychology and political science are the fields that seem to dominate understanding of human dimensions in leading scientific journals, policy debates, media reporting and public discussions of global environmental change. This may bring lustre and influence to those disciplines, but at what cost to environmental social science as a whole, and to the societies our research is intended to assist?

The joint Collection is symptomatic of a problem that needs to be addressed by all those researchers who care about our planetary future. Global environmental change is so profound that it impinges on every conceivable aspect of society - material, moral, aesthetic and spiritual. As last year's Papal encyclical on climate change reminded us, it raises fundamental questions about human needs, wants and desires in a world of ethnolinguistic diversity and acute economic inequality. In its myriad forms environmental social science, as well as the environmental humanities, must be part of the 'conversation of humankind' that we desperately need. This is because it illuminates all aspects of the human condition, recognizing that deep disagreement and divergent demands are an ineluctable part of that condition. The conversation must pertain to means and ends alike, and must make room for reasoned dissent. It must cover both societal deliberation and societal decisionmaking, recognizing that many people are relatively powerless and lack representation. Science-minded social scientists cannot speak for 'people disciplines' as a whole, neither by design nor by default.

Journals such as Nature Climate Change have their part to play in widening the circle of intellectual conversants. But so too do those social researchers who have thus far lacked the luck, energy or confidence to get their work noticed outside the usual academic journals and conferences. The environmental social sciences at large cannot represent themselves: they need articulate spokespeople to advocate for them so that people and planet enjoy the consequent benefits.

\footnotetext{
References

1. Castree, N. et al. Nature Clim. Change 4, 763-768 (2014).

2. Hulme, M. Nature Clim. Change 1, 177-179 (2011).

3. Carey, M., James, L. C. \& Fuller, H. A. Nature Clim. Change 4, 1038-1039 (2014).

4. Hackmann, H., Moser, S. C. \& St. Clair, A. L. Nature Clim. Change 4, 653-655 (2014)

5. Geels, F., Berkhout, F. \& van Vuuren, D. P. Nature Clim. Change 6, 576-583 (2016)

6. Bhaskar, R. Reclaiming Reality (Verso, 2011).

7. Vaccaro, I., Smith, E. A. \& Aswani, S. Environmental Social Sciences (Cambridge Univ. Press, 2012).

8. Moran, E. Environmental Social Science (Wiley-Blackwell, 2010).

9. Benton, T. \& Craib, I. Philosophy of Social Science (Palgrave Macmillan, 2010)

10. Fay, B. Contemporary Philosophy of Social Science (Wiley-Blackwell, 1996).

11. Blue, G. Framing climate change for public deliberation. J. Environ. Pol. Plann. 18, 67-84 (2016).
}

Noel Castree

School of Geography and Sustainable

Communities, University of Wollongong,

Wollongong, New South Wales 2522, Australia. e-mail: ncastree@uow.edu.au 